\title{
Global research output of green chemistry research: a scientometrics study
}

\begin{abstract}
Soheil Sadi-Nezhad ${ }^{a^{*}}$
${ }^{a}$ Department of Statistics and Actuarial Science, University of Waterloo, Waterloo, Canada

\begin{tabular}{l}
\hline C H R O N I C L E \\
\hline Article history: \\
Received January 15, 2019 \\
Received in revised form \\
February 29, 2019 \\
Accepted March 29, 2019 \\
Available online \\
March 30, 2019 \\
\hline Keywords: \\
Green chemistry \\
TOPSIS \\
Scientometrics study \\
\hline
\end{tabular}

A B S T R A C T

Green or sustainable chemistry, is an area of science focused primarily on development of products and processes to reduce the use and generation of hazardous materials. This paper presents a survey on 15643 articles published on Scopus database over the period 1990-2019. The study uses a multi criteria decision making (MCDM) technique named "The Technique for Order of Preference by Similarity to Ideal Solution (TOPSIS)" to rank the 20 countries that are responsible for publication of 14870 articles. The study uses three criteria; namely $h$-index, $I-100$ and the highest cited article for ranking different countries. The results indicate that India with 2655 articles was considered the first country followed by the United States with 2367, Germany with 611 and United Kingdom with 693 articles.
\end{abstract}

C) 2019 by the authors; licensee Growing Science, Canada.

\section{Introduction}

Green or sustainable chemistry, is an area of science focused primarily on development of products and processes to reduce the use and generation of hazardous materials ${ }^{1}$. The primary objectives of green chemistry to reach more resource-efficient and inherently safer design of molecules, materials, products, and processes, which can be accomplished in different contexts. Green chemistry tries to reduce pollution at the molecular scale by applying the concept in different areas of chemistry. Green chemistry also reduces the use of raw materials and helps use environmental friendly goods and materials ${ }^{1}$. According to Rockström et al. ${ }^{2}$, we have seen a relatively stable environment during the last ten thousand years, however, industrial revolution has tremendously changed our planet and human nature faces with several climate changes that could endanger our generation. Therefore, there is a need to reduce the harmful effects of human built goods and materials though green chemistry. For the past two decades, green chemistry has explained how basic scientific techniques can help human health and the environment, significantly ${ }^{3}$. There has been substantial progress in various studies, such as catalysis, the design of safer chemicals and environmentally benign solvents, and the development of renewable feedstocks ${ }^{3}$. Green chemistry leads for the development of the next generation of materials, products, and processes ${ }^{4-6}$. According to Mohanty et al. ${ }^{4}$ " "Biodegradable plastics and bio-based polymer products based on annually renewable agricultural and biomass feedstock can form the basis for a portfolio of sustainable, eco-efficient products that can compete and capture markets currently dominated by products based exclusively on petroleum feedstock".

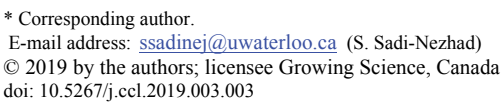


This paper presents a scientometrics analysis on all papers with the keyword of "Green chemistry" published from 1990 to March, 2019 in different peer reviewed journals which are indexed in Scopus database. The study selects all papers with the word "Green chemistry" in keyword, title or abstract of the articles and determines 15643 papers. The survey has sorted on the order of citation records from the highest to the lowest. Next, the study determined that 14870 articles, representative of $95 \%$ of the published articles, belong to 20 countries. Thus, we have used a multi criteria decision making (MCDM) technique named The Technique for Order of Preference by Similarity to Ideal Solution (TOPSIS $)^{7}$ to rank the 20 countries based on three criteria; namely, $h$-index, $I-100$ and the highest cited article. In our study, the number of publications with at least 100 citations represents $I-100$ index while $h$-index is determined as the maximum value of $h$ so that the given author(s) has published $h$-articles which have been cited at least $h$ times. The highest citation is also determined after filtering the data based on each country and considering the first highly cited article.

\section{TOPSIS}

The Technique for Order of Preference by Similarity to Ideal Solution (TOPSIS) ${ }^{7}$ is one of the wellknown multi-criteria decision making (MCDM) techniques used for ranking different alternatives based on different criteria. The method is based on the concept that the chosen alternative ought to have the shortest geometric distance from the positive ideal solution and the longest geometric distance from the negative ideal solution ${ }^{8}$. The TOPSIS procedure consists of the following steps:

1- Calculated the normalized matrix; the normalized value $X_{i j}$ is measured by the following phrase:

$$
x_{i j}=\frac{f_{i j}}{\sqrt{\sum_{j=1}^{i} f_{i j}^{2}}}
$$

2-Calculate the weighted normalized decision matrix. The weighted normalized value $V_{i j}$ is computed as follows:

$$
V_{i j}=w_{i} * x_{i j}
$$

3- Determine the ideal and negative-ideal solution, $f^{*}$ and $f^{-}$.

4- Calculate the separation measures, using the $\mathrm{n}$ dimensional Euclidean distance. The separation of each alternative from the ideal solution is given as:

$$
\begin{aligned}
& S_{j}^{*}=\sqrt{\left(v_{i j}-v_{i}^{*}\right)^{2}} \\
& S_{j}^{-}=\sqrt{\left(v_{i j}-v_{i}^{-}\right)^{2}}
\end{aligned}
$$

5- Calculate the relative closeness to the ideal solution. The relative closeness of the alternative:

$$
C_{j}^{*}=\frac{S_{j}^{-}}{S_{j}^{-}+S_{j}^{*}}
$$

6- Rank the preference order.

TOPSIS method has been widely used for ranking different alternatives according to several criteria. Sadatrasool et $\mathrm{al}^{8}{ }^{8}$, for instance, used TOPSIS for ranking project manager selection. Chakraborty et al. ${ }^{9}$ implemented a fuzzy TOPSIS method in order to rank Cricket teams in India. 


\section{Research methodology}

The proposed study of this paper considers the same weights for all three criteria (i.e. $w_{1}=w_{2}=w_{3}$ ). In many applications, decision maker's opinions are gathered to measure the relative importance of different criteria ${ }^{10}$. Table 1 demonstrates the data used for the implementation of TOPSIS technique.

Table 1

The summary of the data used for ranking countries on the basis of Green Chemistry

\begin{tabular}{lcccc}
\hline Country & Publications & h-index & I-100 & High \\
\hline India & 2655 & 219 & 693 & 722 \\
China & 2426 & 100 & 103 & 1551 \\
USA & 2367 & 136 & 184 & 3856 \\
Iran & 1136 & 52 & 17 & 893 \\
France & 712 & 70 & 42 & 1289 \\
UK & 693 & 80 & 65 & 3856 \\
Spain & 634 & 61 & 30 & 673 \\
Brazil & 628 & 40 & 5 & 282 \\
Germany & 611 & 81 & 64 & 3856 \\
Italy & 585 & 54 & 29 & 747 \\
Japan & 522 & 67 & 47 & 650 \\
South Korea & 407 & 46 & 17 & 1119 \\
Canada & 378 & 51 & 19 & 913 \\
Saudi Arabia & 285 & 35 & 8 & 759 \\
Poland & 257 & 35 & 13 & 355 \\
Sweden & 133 & 26 & 8 & 3856 \\
Greece & 126 & 19 & 6 & 440 \\
Argentina & 119 & 30 & 2 & 182 \\
Singapore & 101 & 31 & 13 & 365 \\
Austria & 95 & & 11 & 319 \\
\hline & & 13 & &
\end{tabular}

According to Table 1, India, a developing country, is responsible for publication of 2655 articles followed by China with 2426 articles and the United States with 2367 research papers. For the proposed method of this paper, total number of publications is not accounted as a criterion for ranking method. Fig. 1 shows the results of ranking of various countries based on the implementation of TOPSIS method.

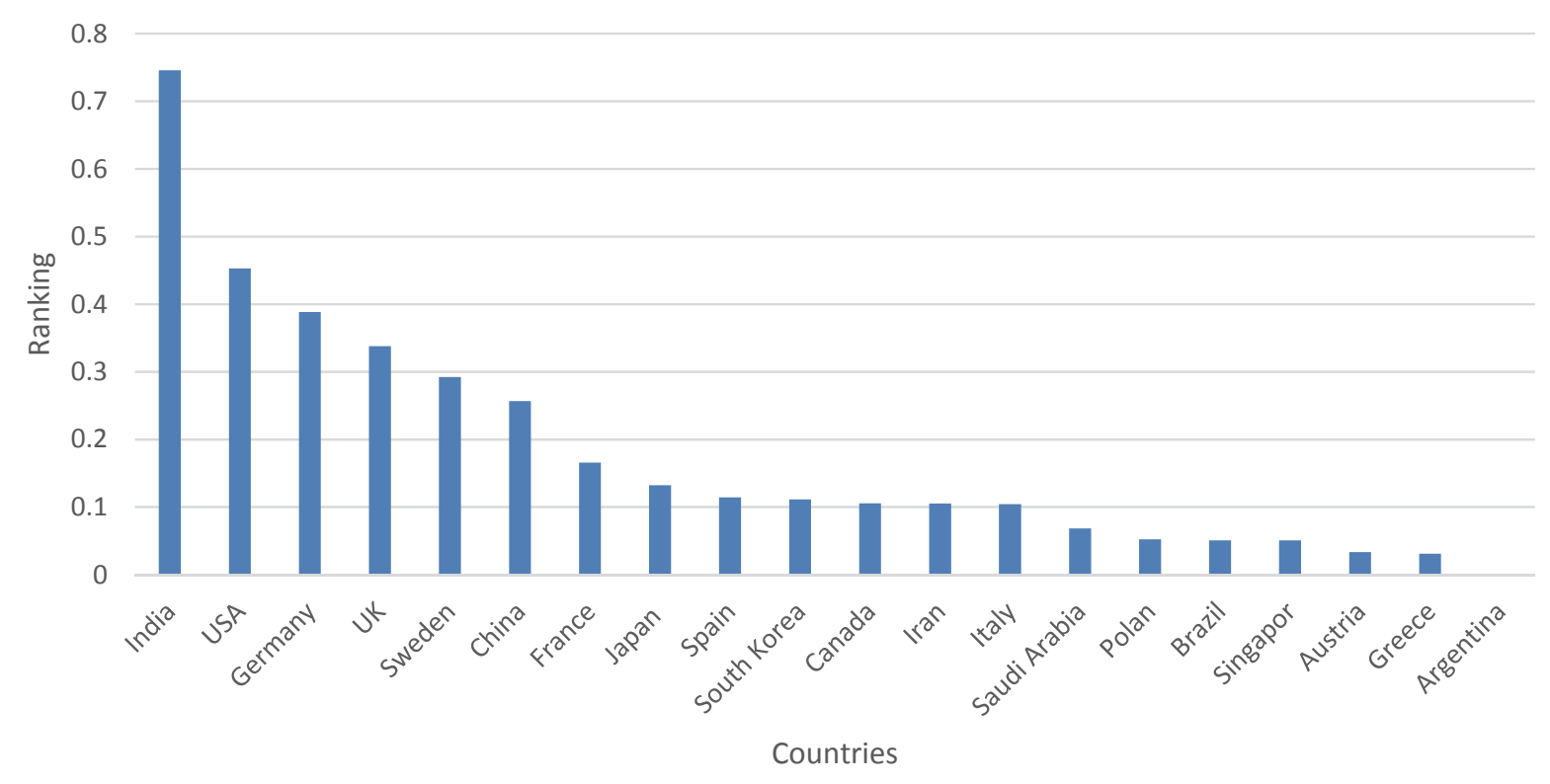

Fig. 1. The results of ranking of 20 countries based on three criteria 


\section{Discussion and conclusion}

According to the results given in Fig. 1, India is placed number one country for presenting high quality articles followed by the United States, Germany and United Kingdom. In our survey, China has successfully published 2426 articles, which is number two in terms of quantity. However, when it comes to quality figures, i.e. $h$-index, $I-100$, etc., the country has appeared in sixth position. On the other hand, Sweden only published 133 articles during the course of the study but the scientists in this country managed to publish some joint studies with researchers from the United States and Germany, which received significant number of citations ${ }^{2}$. This helped the country to be listed in the best five countries in terms of publishing high quality articles. We hope this survey encourages researchers to focus on publishing high quality articles in the scope of Green Chemistry to help keep our environment more stable and safe.

\section{Acknowledgement}

The authors would like to thank the anonymous referees for constructive comments on earlier version of this paper.

\section{References}

1. Sheldon, R. A., Arends, I., \& Hanefeld, U. (2007). Green chemistry and catalysis. John Wiley \& Sons.

2. Rockström, J., Steffen, W., Noone, K., Persson, Å., Chapin III, F. S., Lambin, E. F., ... \& Nykvist, B. (2009). A safe operating space for humanity. Nature, 461(7263), 472.

3. Anastas, P. T., \& Kirchhoff, M. M. (2002). Origins, current status, and future challenges of green chemistry. Acc. Chem. Res., 35(9), 686-694.

4. Mohanty, A. K., Misra, M., \& Drzal, L. T. (2002). Sustainable bio-composites from renewable resources: opportunities and challenges in the green materials world. J. Polym. Env., 10(1-2), 1926.

5. Farrusseng, D., Aguado, S., \& Pinel, C. (2009). Metal-organic frameworks: opportunities for catalysis. Angew. Chem. Int. Ed., 48(41), 7502-7513.

6. Gallezot, P. (2012). Conversion of biomass to selected chemical products. Chem. Soc. Rev., 41(4), $1538-1558$.

7. Yoon, K. P., \& Hwang, C. L. (1995). Multiple attribute decision making: an introduction (Vol. 104). Sage publications.

8. Sadatrasool, M., Bozorgi-Amiri, A., \& Yousefi-Babadi, A. (2016). Project manager selection based on project manager competency model: PCA-MCDM Approach. J. Proj. Manag., 1(1), 7-20.

9. Chakraborty, S., Kumar, V \& Ramakrishnan, K. (2018). Selection of the all-time best World XI Test cricket team using the TOPSIS method. Dec. Sci. Lett., 8(1), 95-108.

10. Sadjadi, S., \& Karimi, M. (2018). Best-worst multi-criteria decision-making method: A robust approach. Dec. Sci. Lett., 7(4), 323-340.

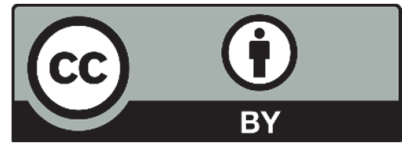

(C) 2019 by the authors; licensee Growing Science, Canada. This is an open access article distributed under the terms and conditions of the Creative Commons Attribution (CC-BY) license (http://creativecommons.org/licenses/by/4.0/). 